\title{
Fabrication of aerosol-based nanoparticles and their applications in biomedical fields
}

\author{
Milan Gautam ${ }^{1} \cdot$ Jong Oh Kim ${ }^{1} \cdot$ Chul Soon Yong ${ }^{1}$
}

Received: 6 February 2021 / Accepted: 17 March 2021 / Published online: 12 May 2021

(c) The Korean Society of Pharmaceutical Sciences and Technology 2021

\begin{abstract}
Background Traditionally, nanoparticles for biomedical applications have been produced via the classical wet chemistry method, with size control remaining a major problem in drug delivery. In recent years, advances in aerosol-based technologies have led to the development of methods that enable the production of nanosized particles and have opened up new opportunities in the field of nano-drug delivery and biomedicine. Aerosol-based technologies have been constantly used to synthesize multifunctional nanoparticles with different properties, which extends their possible biological and medicinal applications. Moreover, aerosol technologies are often more beneficial than other existing approaches because of the major disadvantages of these other techniques.

Area covered This review provides a brief discussion of the existing aerosol-based nanotechnologies and applications of nanoparticles in a variety of diseases. Various types of nanoparticles, such as graphene oxide, Prussian blue, black phosphorous, gold, copper, silver, tellurium, iron oxide, titania, magnesium oxide, and zinc oxide nanoparticles, prepared using aerosol technologies are discussed in this review. The different tactics used for surface modifications are also outlined. The biomedical applications of nanoparticles in chemotherapy, bacterial/fungal/viral treatment, disease diagnosis, and biological assays are also presented in this review.

Expert opinion Aerosol-based technologies can be used to design nanoparticles with the desired functionality. This significantly benefits the nanomedicine field, particularly as product parameters are becoming more encompassing and exacting. One of the biggest issues with conventional methods is their scale-up/scale-down and clinical translation. Aerosol-based nanoparticle synthesis helps enhance control over the product properties and facilitate their use for clinical applications.
\end{abstract}

Keywords Aerosol $\cdot$ Spark discharge $\cdot$ Biomedical $\cdot$ Atomization $\cdot$ Pyrolysis $\cdot$ Theragnostic

\section{Introduction}

Organic and inorganic nanoparticles are the most widely investigated nanomaterials and are particularly important in nanotechnologies. Different synthetic routes have been developed to fabricate the desired metallic nanomaterials, such as wet chemical methods or physical processing, mechanical milling, or high-vacuum temperature techniques (Byeon and Kim 2012). Chemical processing methods require expensive chemical precursors and solvents in liquid or gaseous forms to prepare nanocomposites. Although various physical and chemical methods have been adopted

Chul Soon Yong

csyong@ynu.ac.kr

1 College of Pharmacy, Yeungnam University, 214-1

Dae-Dong, Gyeongsan 712-749, Republic of Korea to synthesize different nanocomposites, these methods are still limited as they involve sophisticated setups, a significant amount of chemical waste, the production of partly contaminated particles, and difficulty in handling toxic chemicals (Messing 2015; Khan et al. 2019). Mechanical milling techniques are cost-effective, reliable, easy to operate, and applicable in both dry and wet conditions. However, possible contamination due to the use of surfactants, the formation of irregular shapes, and long cleaning times limit their application (Piras et al. 2019). The direct mixing and dispersion of materials depend on the physicochemical properties of the materials employed, which can hinder the fabrication of the desired nanoparticles in the case of unfavorable combinations. A significant drawback of these techniques is the introduction of impurities that are often more abundant in liquids than in gases. Due to these shortcomings, researchers have focused on developing more convenient 
fabrication techniques for selective drug delivery and biomedical applications.

Recently, the aerosol-based (gas phase) preparation technique has gained popularity due to its simplicity, good control over particle shape and size, low cost, versatility, and ability to generate pure particles with a nominal effect on the environment. This aerosol-based technique offers highpurity nanoparticles and can be used to synthesize nanoparticles in a continuous process. In contrast to traditional wet chemical methods, aerosol-based methods involve a limited number of fabrication steps (Shields et al. 2010). This system has been widely adopted on a commercial scale because it allows the direct collection of nanoparticles in one step and produces low waste when compared to wet chemical processes (Filho et al. 2020).

The aerosol-based technique involves different mechanisms which are used to generate specific nanostructures via vapor deposition, measurement of particle size in the aerosol state, or by use of other chemical properties (Wang et al. 2020). Aerosol-based nanoparticles can be prepared using a variety of methods, depending on the desired composition, shape, and size (An et al. 2010). Moreover, preparation techniques can be easily manipulated to prepare specific gas-suspended vapor structures, making this method broadly applicable in the field of nanotechnology. Aerosolbased techniques have been widely used for the preparation of optoelectronic and nanoelectronic devices, which have been shown to have enhanced catalytic and gas-sensing properties (Shandilya et al. 2014). In addition, aerosol-based materials are extensively employed in the biomedical field for cancer treatment, as well as for their antibacterial activity (Athanassiou et al. 2010). Due to the properties of organic or inorganic nanoparticles, they have also been utilized for the treatment of various disease models. In this paper, we outline the different methods used for the preparation of aerosol-based nanoparticles and also describe the use of these nanoparticles for biomedical applications.

\section{Fabrication of aerosol-based nanocomposites}

The preparation of nanoparticles via aerosol-based technologies provides a powerful method for the fabrication of nanoconstructs with precise morphology and chemical composition. Aerosol-based nanoparticles can be synthesized by either atomizing a solution with a defined composition to form fine droplets that crystallize to solid nano-constructs upon the subsequent evaporation of the solvent or by aeroto-particle conversion through nucleation and growth via condensation and coagulation, respectively (Graves et al. 2020a, b; Mohammadi 2020). Atomization of different types of solutions can be achieved either by nebulization or electrohydrodynamic atomization, while aero-to-particle preparation can be accomplished via spark discharge, flame, furnace or plug-in-play plasma techniques. Of the various methods presented, some aerosol-based techniques are outlined and discussed in detail below.

\section{Atomization of liquid solvents}

Different techniques, such as electrospray, ultrasound, and pneumatic atomization, can be used to generate aerosol particles by atomizing solvents with a specific chemical composition (Wang et al. 2008; Kim et al. 2017). In this technique, the main principle behind nanoparticle formation is that upon the evaporation of the solvent in the atomized droplets (1-10 $\mu \mathrm{m}$ in diameter), the droplets crystallize to form a solid nanocomposite. In liquid atomization, a liquid feed is broken into fine droplets using a nozzle. Different atomizers, such as hydraulic pressure, pneumatic, ultrasonic nozzle, or rotary disk atomizers, can be employed to produce fine droplets of different sizes (Yu Vasilyev et al. 2019). Pneumatic atomizers are typically used for pharmaceutical applications due to their suitability (twin-fluid nozzles). These atomizers are commonly used because they can be effectively exploited in small-scale plants to generate smaller droplets (Kemp et al. 2013). In a previous report, silica nanoparticles were synthesized via flame pyrolysis using a twofluid nozzle spray (Chang et al. 2008), as shown in Fig. 1. Tetraethyl orthosilicate was dissolved in ethanol and used as a silica precursor. Then, the liquid phase precursor solution

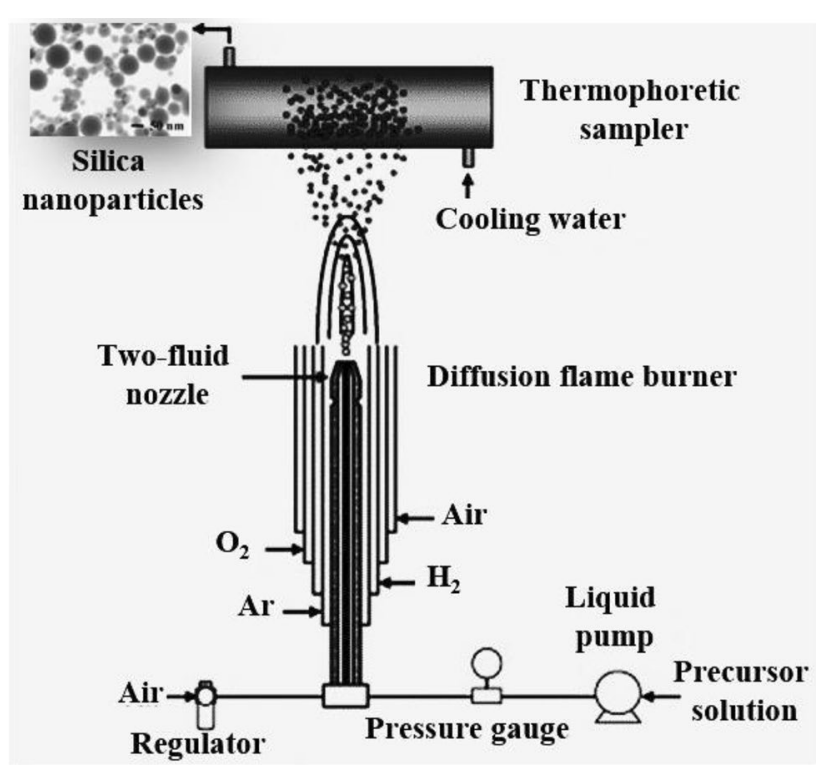

Fig. 1 A schematic diagram of the experimental apparatus for the synthesis of silica nanoparticles via flame spray pyrolysis using a two-fluid nozzle spray. The given figure was adopted from Chang et al. (2008) 
was sprayed through a two-fluid nozzle, with the flame being generated by the combustion of the precursor, argon, hydrogen, oxygen, and air, which were separately passed through four concentric stainless tubes. Finally, the silica nanoparticles were collected by solvent evaporation, precipitation, decomposition, and oxidation of the solute particles.

\section{Spark-discharge generator}

This method involves the generation of aerosol vapors from different materials via spark discharge. Plasma techniques have been adopted to prepare organic or inorganic nanoparticles containing biological materials. In this method, two different conducting electrodes are heated up to $20,000 \mathrm{~K}$ and nanoparticles are obtained via vapor displacement through thermophoretic deposition (Gautam et al. 2019a, b). The vapor can be generated by placing a different pair of electrodes with a continuous power supply, following which the vapor is passed through a thermal reactor for vapor deposition. The ambient heterogeneous spark discharge technique has been used to synthesize gold $(\mathrm{Au})$ and $\mathrm{Au}$-titanium dioxide $\left(\mathrm{Au}-\mathrm{TiO}_{2}\right)$ nanoparticles used for photothermal therapy against cancer cells, as shown in Fig. 2 (Byeon and Kim 2014). The electrical current on the two different titanium (Ti) and $\mathrm{Au}$ rods was used to vaporize the $\mathrm{Ti}$ and $\mathrm{Au}$ under a continuous airflow to produce ultrafine Au nanoparticles (lateral dimension of approximately $2 \mathrm{~nm}$ ). Furthermore, these ultrafine nanoparticles were then patched up with $\mathrm{TiO}_{2}$ nanoparticles to form $\mathrm{Au}-\mathrm{TiO}_{2}$ heterodimers (lateral dimension of approximately $38 \mathrm{~nm}$ ), which were then used to induce apoptosis under visible light in HeLa cells.

In addition, the significant toxicity of silver $(\mathrm{Ag})$ and copper $(\mathrm{Cu})$ nanoparticles in humans has been reduced by designing metal-doped tellurium (Te) nanoparticles, which were used as antibacterial agents in one study (Park et al. 2019). The safe-by-design plug-and-play technique was employed under a continuous nitrogen flow to produce $\mathrm{Ag}$ (or $\mathrm{Cu}$ )-doped $\mathrm{Te}(\mathrm{Ag}$ - or $\mathrm{Cu}-\mathrm{Te}$ ) nanoparticles with antibacterial activity and better safety (Fig. 3). Moreover, the ratio between individual $\mathrm{Ag}$ or $\mathrm{Cu}$ can be modulated (5-8\% atomic $\mathrm{Ag}$ and $\mathrm{Cu}$ ) to prepare biocompatible metal-doped nanoparticles with enhanced antibacterial activity. The prepared nanoparticles were shown to exhibit an optimal safety index and significantly decreased the minimum inhibitory concentration of the individual $\mathrm{Te}$ nanoparticles.

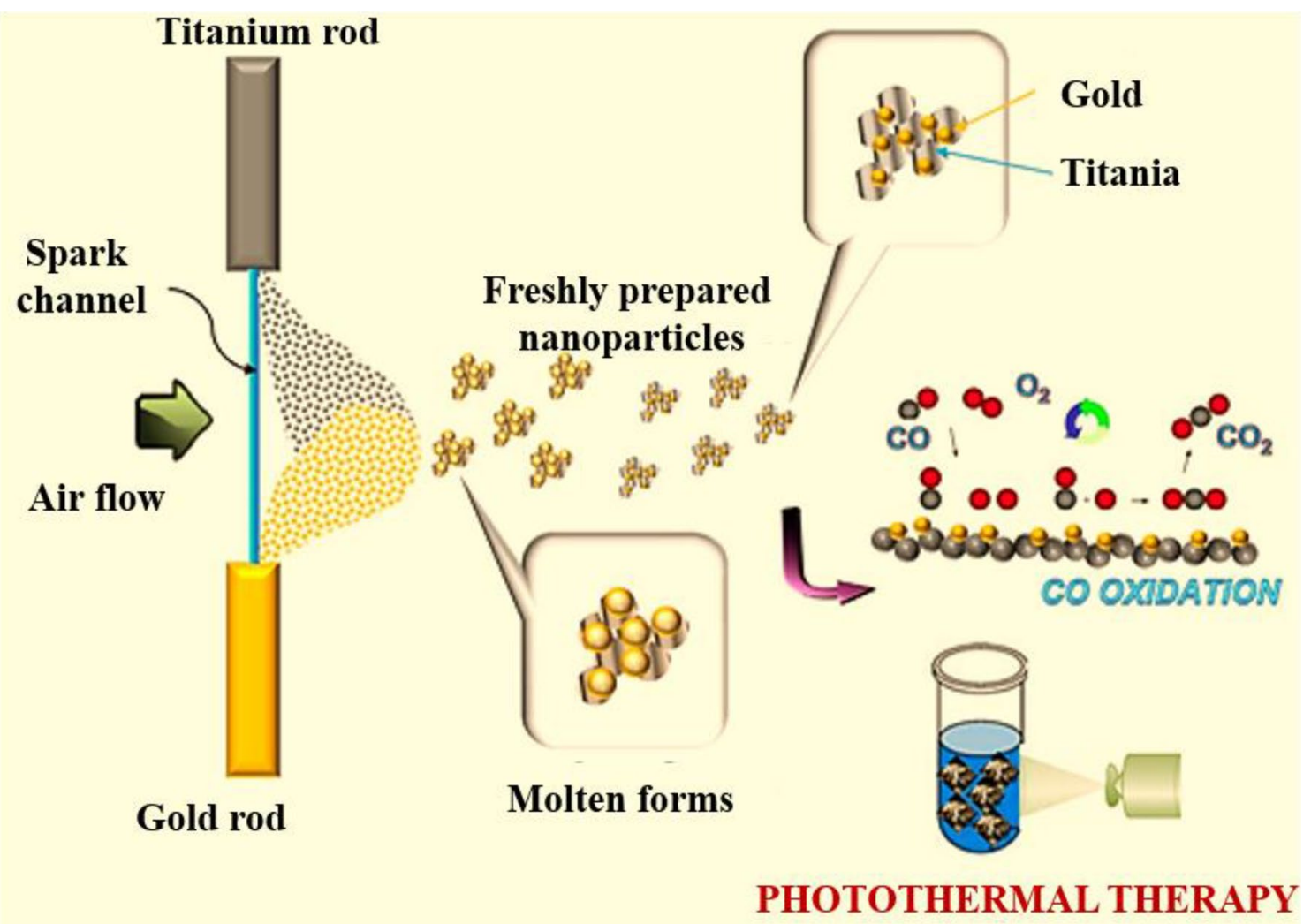

Fig. 2 Ambient heterogeneous spark discharge to synthesize $\mathrm{Au}-\mathrm{TiO}_{2}$ heterodimers in a gaseous phase for photocatalytic and photothermal applications. The given figure was adopted from Byeon and Kim (2014) 


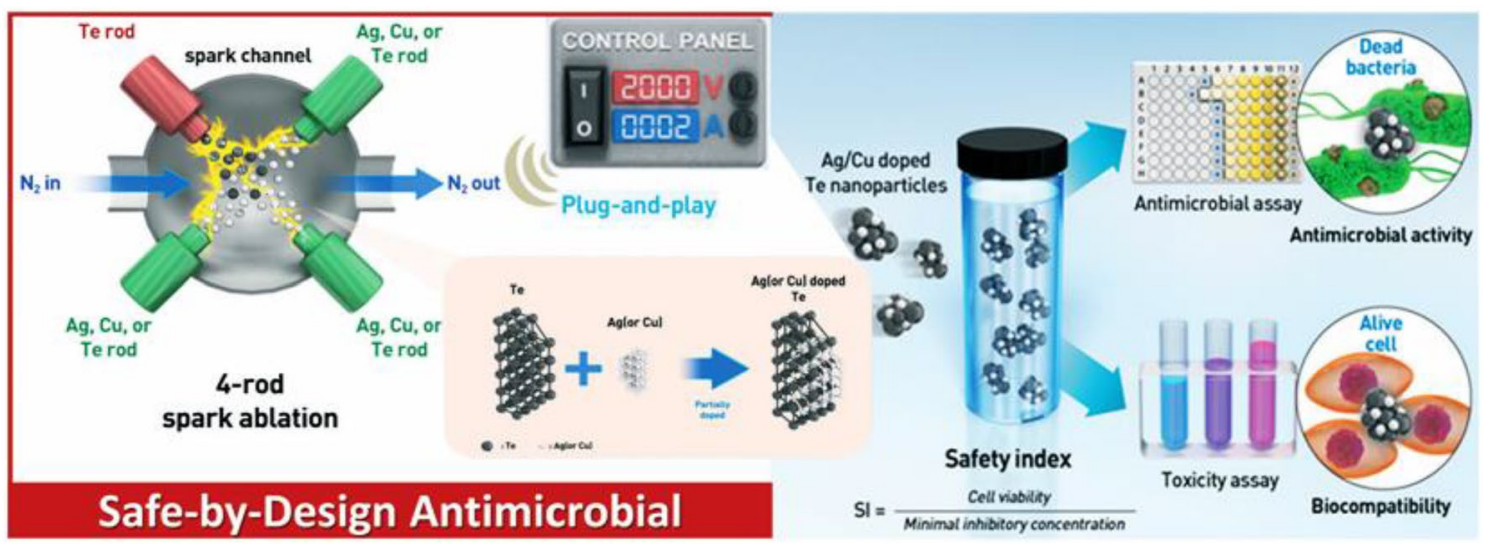

Fig. 3 Schematic of spark ablation used to prepare $\mathrm{Ag}$ or $\mathrm{Cu}$-doped Te nanoparticles from three $\mathrm{Ag}$ or $\mathrm{Cu}$ anodes (green) and a Te cathode (red) inside a chamber under a nitrogen gas flow. The given figure was adopted from Park et al. (2019)

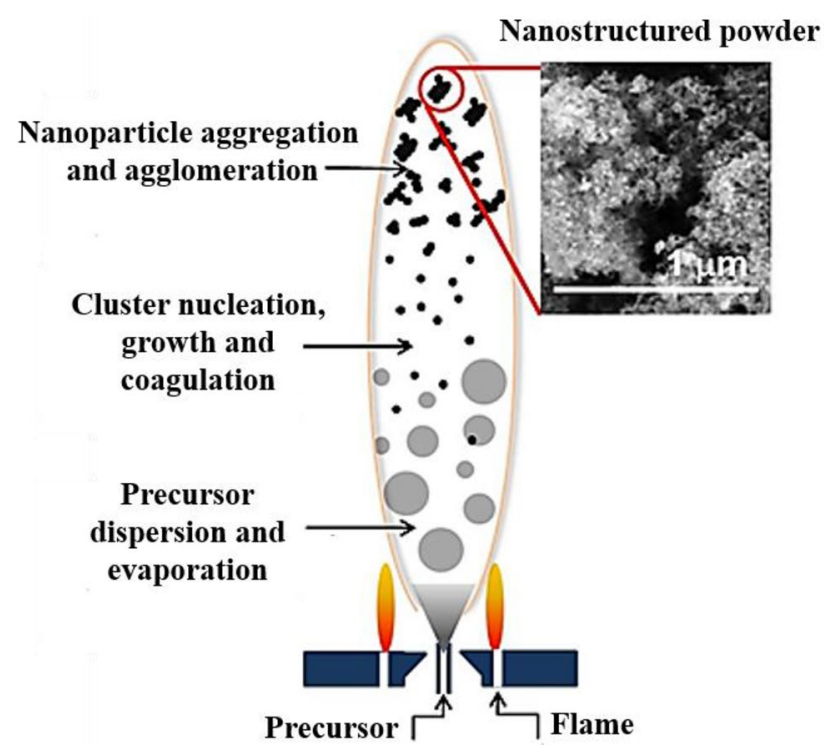

Fig. 4 Schematic of the preparation of nanoparticles via flame spray pyrolysis. The given figure was adopted from Bettini et al. (2015)

\section{Flame spray pyrolysis}

Flame spray pyrolysis generates nanoparticles in the gaseous phase at high temperatures using a flame. This technique involves the deposition of thin oxide films onto a substrate via the evaporation and decomposition of sprayed liquid precursors. This process is based on the exothermic combustion of the liquid phase, followed by evaporation, oxidation, and nucleation under a high flame to form subsequent solid nanoparticles via coagulation, sintering/coalescence, and agglomeration (Teoh et al. 2010; Meierhofer et al. 2020), as shown in Fig. 4. The diameter and structure of the produced nanoparticles are dependent on the feed rates of the liquid precursor and oxygen, as well as the atomizer nozzle configuration.

Based on this mechanism, on-demand nanoplatforms have been synthesized for combination cancer therapy (Gautam et al. 2018). Near-infrared (NIR) responsive chemophotothermally active nanoparticles were designed using an aero-hydro-aero single-pass production system. In this system, the inorganic core of titanium peroxide $\left(\mathrm{yTiO}_{2}\right)$ was prepared via flame pyrolysis of vaporized $\mathrm{TiCl}_{4}$, subsequently followed by ultrasonic $\mathrm{H}_{2} \mathrm{O}_{2}$ treatment. Then, the nanocomposite was synthesized by patching it up with graphene oxide (GO), which is a photoactivable agent, doxorubicin (D), which is a chemotherapeutic agent, and a stealth agent, namely polyethylene glycol (P), as shown in Fig. 5. The prepared nanoparticles were shown to exhibit a greater photothermal effect and selective tumor distribution, with enhanced tumor cell killing activity in SCC-7 carcinoma cells.

Magnetic nanoparticles encapsulated in a silica matrix $\left(\mathrm{C} / \mathrm{SiO}_{2} @ \mathrm{Fe}\right.$ composites $)$ can also be prepared via carbon laser (1500 W CW)-induced pyrolysis of aerosols and can be used as contrast agents for magnetic resonance imaging (MRI) or magnetic hyperthermia (Veintemillas-Verdaguer et al. 2007). To prepare the contrast agent, ferrocene, an organometallic compound, is nebulized with a toluene solution in the presence of tetraethoxysilane to form the aerosol. The aerosol is then passed into the reaction chamber via gas influx and the nanosized particles are then obtained through pyrolysis using a carbon laser beam.

\section{Plasma synthesis}

Plasma science is another emerging field in nanoparticle synthesis. The multifunctional synthetic approach is one of the most used systems in biomedicine, polymer science, industrial sterilization, and food safety. Two types of plasma 
Fig. 5 Schematic of the aerohydro-aero route to produce graphene oxide-patched titania nanoparticles for chemo-phototherapeutic applications. The given figure was adopted from Gautam et al. (2018)

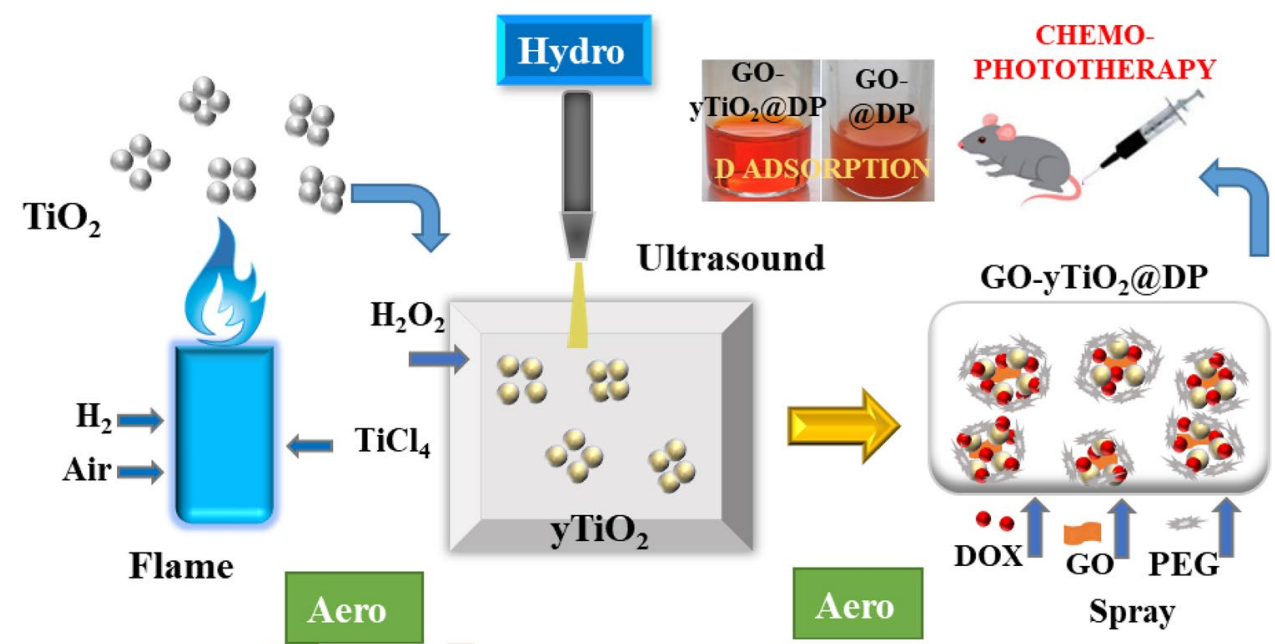

(thermal and non-thermal) can be used to prepare different types of nanocomposites. In thermal plasma, the temperatures of gas molecules and free electrons are approximately identical, whereas in non-thermal plasma, free electrons have a temperature of several electron volts, while the overall gas temperature is close to or slightly above room temperature. Moreover, non-thermal plasma can be generated at both low and atmospheric pressure (Palma et al. 2020; Stryczewska 2020).

In non-thermal plasma, volatile precursors (hydrocarbons, volatile silicon compounds, Ti or metal halides) are passed into the plasma chamber as vapor, along with the carrier gas (Blanquart and Roest 2019). In the plasma chamber, the introduced precursor vapor is dissociated by the energetic species to form silicon atoms or metal aerosols. Because of the overall low gas temperature, these atoms quickly nucleate to form a cluster and then grow into nanoparticles due to the continuous condensation of vapors. In the case of hydrocarbons, they tend to polymerize to form nanocomposites under the influence of active species (Kakiuchi et al. 2013; Naz et al. 2020). Titanium has a broad range of applications, being used in solar cells, electronics, biomedicine, and photocatalysis. Hence, thin Ti films have been synthesized using non-thermal atmospheric pressure plasma deposition methods, which are generally used in various fields (Banerjee et al. 2020). Photoluminescent silicon nanoparticles have been prepared by using the non-thermal plasma technique and tested for their use as potential sensors and optoelectronics, as well as for their potential applications in medicine and natural sciences (Müller et al. 2020). In this system, silica nanoparticles are prepared using low-pressure radio frequency plasma in a flow-through glass tube reactor, followed by surface modifications in both air and vacuum chambers. Au nanoparticles have also been fabricated using the pulse-modulated radio-frequency atmospheric pressure glow discharge technique. The fabricated Au nanoparticles were then further passed into an aqueous gelatin solution and turmeric oil to prepare an oil-in-water nanoemulsion. Interestingly, the prepared nanoemulsion showed enhanced cytotoxic activity against two breast cancer cell lines, namely MDA-MB-231 and MCF-7 (Dzimitrowicz et al. 2020). Moreover, other non-thermal plasma techniques have been used to produce carbon, iron, and palladium nanoparticles (Chawdhury et al. 2020; Li et al. 2020).

Various types of materials can be processed through the thermal plasma technique, which has been considered as a more efficient, attractive, and active technique in the industrial and biomedical fields. Thermal plasma synthesis involves the dissociation of precursors (gas, liquid, or solid phase) under highly reactive and extremely high-temperature conditions. Due to the extremely high temperatures, solidphase compounds evaporate into micron-sized solid particles in their aerosol state and then recondense under controlled conditions to form nanoparticles. This process is performed mainly in inductively coupled radiofrequency plasma torches (Kim et al. 2020) and thermal microwave plasmas (Graves et al. 2020a, b). Titanium boride nanoparticles (10-30 nm in diameter) have been prepared using radiofrequency induction thermal plasma techniques, by introducing and rapidly evaporating titanium and boron powder in a plasma reactor to form nanoparticles by using a quenching process (Cheng et al. 2012). Moreover, their applications in various fields have been investigated. Zinc oxide nanosheets (approximately $25 \mathrm{~nm}$ ) were also prepared using the thermal plasma technique and their fluorescence quenching mechanism was studied using $\alpha$-amylase (Khade et al. 2017). Carbonbased nanoparticles have been extensively used in various biomedical fields, such as cancer therapy, drug delivery, theragnostic applications, and biosensors (Gautam et al. 2019a, b; Maiti et al. 2019). Therefore, the radiofrequency thermal plasma technique can be used to prepare extremely thermally stable (up to $500 \mathrm{~K}$ ) carbon-coated magnetic 
nanocomposites, which can have various biomedical applications (Bystrzejewski et al. 2007).

\section{Laser ablation}

Laser-based nanoparticle synthesis is a commonly used technique in the fields of imaging, sensors, catalysis, and biomedicine. It is also frequently used to generate nanoparticles in a gaseous phase. The excimer laser beam is delivered into the ablation chamber through a quartz window to vaporize the solid target material. Due to the effect of the laser beam, the surface of the target material melts and forms vapors when the temperature rises beyond its boiling point. After the application of the carrier gas, the vapors are then transported from the ablation chamber, cooled down to form clusters, and then converted into nanoparticles by the further condensation of the vapors (Ullmann et al. 2002). This method is versatile and the composition of the prepared nanoparticles can be easily modified by changing the target material and varying the pulse energy and frequency of the applied laser (Fazio et al. 2020). Titanium, silicon, aluminum, iron, and tungsten oxide aerosols have been synthesized by reactive laser ablation, using oxygen as the carrier gas. Nanometer-sized aerosols of carbon and $\mathrm{Au}$ were also prepared by non-reactive laser ablation under a continuous flow of nitrogen gas (Ullmann et al. 2002). Recently, the pulsed laser deposition method has been widely utilized to generate thin films for multipurpose applications. This technique has been used to modulate the thickness of inorganic oxide films and its effect on the luminescent properties of these films has also been investigated (Ogugua et al. 2020). Polymer-metal nanoparticles have also been fabricated using UV-pulsed laser deposition, in which metal clusters $(\mathrm{Au}, \mathrm{Cu}$, $\mathrm{Ag}$, or Pd) were deposited onto a polymer [polycarbonate, poly-(methyl methacrylate), or bisphenol A dimethacrylate] surface using a pulsed laser to prepare polymer/metal multilayer nanoparticles (Darwish et al. 2013). However, the concentration of nanoparticles produced using the laser ablation method is often low, thus, making this technique difficult to implement on an industrial scale, as it requires high investment costs due to the high price of a laser system, as well as a considerable amount of energy. Therefore, to be economically convenient, colloids should be prepared in large quantities and fairly frequently (Sportelli et al. 2018).

\section{Application of aerosol-based nanotechnologies}

Aerosol-based nanoparticles have been widely used for therapeutic or theragnostic applications in nanomedicine. Nanocomposites loaded with a therapeutic agent can be delivered efficiently to different organs, either by targeting or non-targeting strategies. The applications of aerosol-based nanoparticles are as follows:

\section{Biomedical applications}

Different organic and inorganic nanoparticles have been synthesized using the aerosol technology and tested for their potential biomedical applications in terms of their biocompatibility, pharmacokinetics, immunogenicity, bioavailability, and toxicity. Their potential applications in various biomedical fields include cancer treatment, antimicrobial applications, clinical diagnosis, protein detection, and different biological assays, as illustrated in Fig. 6.

\section{Cancer treatment}

Various therapeutic nanoparticles have been engineered via aerosol techniques to overcome the shortcomings of cancer monotherapy, and are employed through combination therapies of chemo-phototherapy, photodynamic therapy (PDT), or photo-immunotherapy. These combination therapies help to enhance the therapeutic efficacy of the nanoparticles by reducing off-target effects and tumor-induced immunosuppression. Compared to conventional chemotherapy, PDT is considered a promising noninvasive technique due to its selective and localized therapeutic applications in cancer treatment. In this method, a light-activable photosensitizer agent is delivered into the tumor area, where it induces tumor cell death via elevated temperatures and reactive oxygen species (ROS) production (Poudel et al. 2020). Accordingly, $\mathrm{GO}$ was prepared using the spark discharge technique and patched up with imatinib-loaded mesoporous Ti to form photoactivable nanocomposites. The prepared nanoparticles were then used for the treatment of colorectal cancer, with the chemo-photothermal activity of the nanoparticles being further enhanced after polyethylene glycol (PEG) coating (Gautam et al. 2020a, b).

Although considerable achievements have been made in the development of photodynamic agents in the past decade, a substantial barrier to their clinical translation is their toxicity and efficacy. Hence, clinically translatable nanoparticles were prepared by coating the surface of Prussian blue nanocages, an FDA-approved agent, with GO nanoflakes, which were then used for the treatment of pancreatic cancer. As expected, the temperature of the prepared nanoparticles was significantly enhanced after GO coating and exhibited excellent chemo-photodynamic therapy outcomes in the presence of the chemotherapeutic agent doxorubicin (Gautam et al. 2020a, b). Low tumor penetration of NIR light and thermotolerance after initial therapy has limited the application of PDT in cancer treatment (Vankayala et al. 2014). Various physiological barriers associated with the 
Fig. 6 Biological applications of aerosol-based nanocomposites

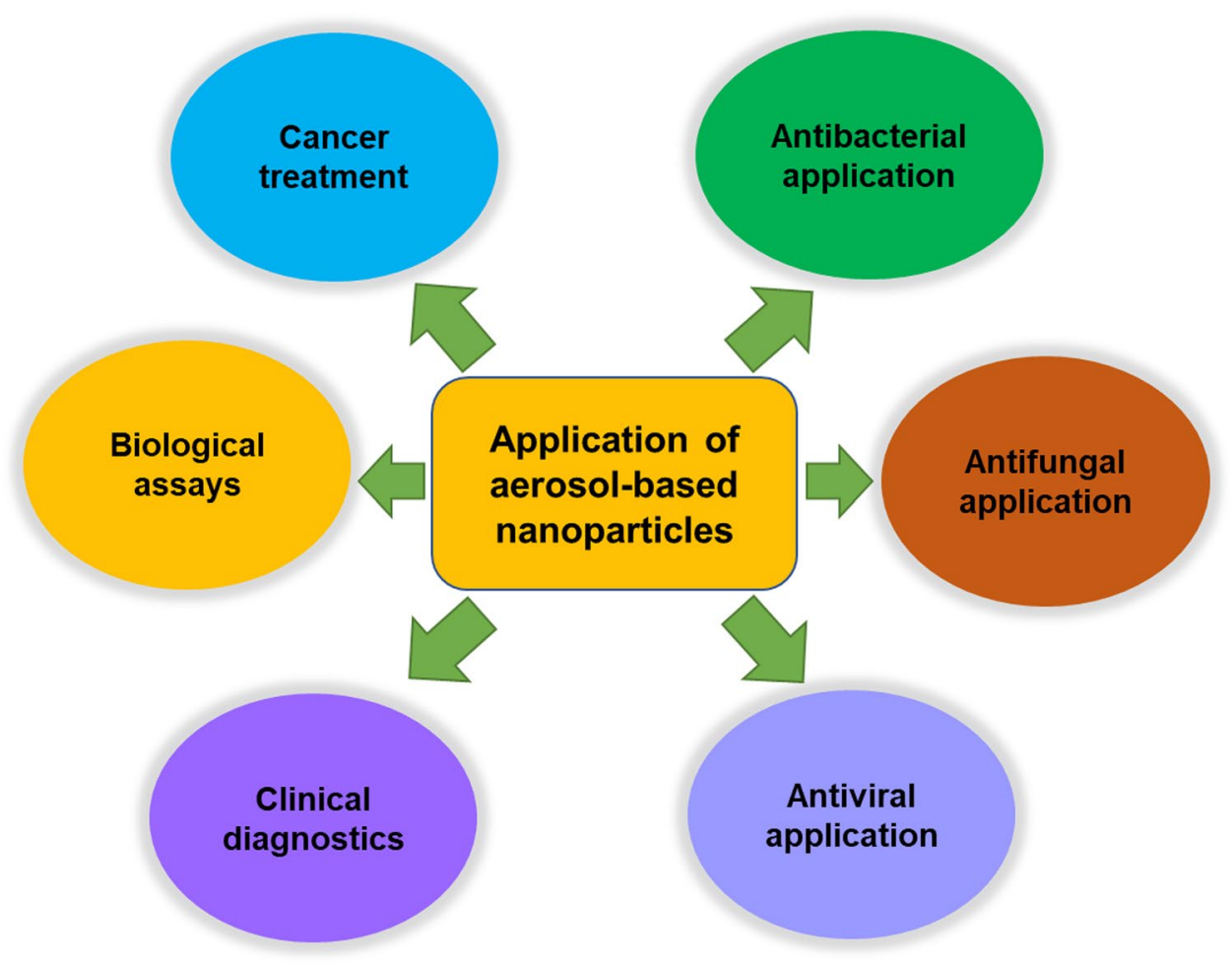

tumor microenvironment can also noticeably hinder the effective delivery of nanoparticles into tumor cells (Zhang et al. 2019). To enhance tumor targetability, various targeting agents have been developed and coated onto the surface of nanocomposites. The attachment of polymeric or biological targeting agents significantly promotes tumor accumulation and reduces their toxic effects in healthy cells. Thus, to adequately deliver GO nanoflakes into the tumor area, the nanoflakes were coated with both PEG and chitosan in the liquid phase and were then administered to treat various cancer types. A biodistribution study demonstrated that the delivery and delivery speed of chitosan-coated nanoparticles into the tumor area were significantly increased compared with the non-coated nanoparticles, therefore leading to an enhanced targeted antitumor effect (Thapa et al. 2017). The use of biodegradable and disintegrable inorganic nanosystems for cancer treatment has become dramatically more frequent due to the nanopaticles' less toxic effects on vital organs.

The use of immune checkpoint blockers (ICBs) and cancer-targeted antibodies has further helped to overcome tumor-induced immunosuppression and non-targeting issues. As such, ICB (PD-L1) and a cancer-targeting antibody (CXCR4) were loaded onto black phosphorous (BP) using plug-and-play devices to prepare photoimmunotherapeutic core-shell nanoparticles containing dabrafenib, which is a B-Raf inhibitor (Nguyen et al. 2019). Upon NIR laser irradiation, the prepared nanoparticles were shown to induce a strong immune response against human skin cancer cells. A core-shell nanocomposite with a base core of poly-L-histidine $(\mathrm{H})$-grafted $\mathrm{BP}$ and a shell consisting of an erythrocyte membrane (BP-H-ILsi-X@EM-YSA) were also prepared for combined chemo-photo-immunotherapeutic applications (Ou et al. 2019). The prepared nanoparticles were then used to treat MC-38 tumors (colon adenocarcinoma). Interestingly, they were shown to have enhanced tumor targetability and endosomal escape, thereby inducing efficient antitumor immune responses. Although many multifunctional nanoparticles have been synthesized for cancer treatment, a key burden is their effective delivery to the tumor sites. Moreover, safety issues remain a major concern for their translation into clinical practice.

\section{Antibacterial applications}

Recent advances in nanotechnology have led to the development of biodegradable antibacterial agents and synthetic approaches to effectively address bacterial resistance issues. Many obstacles, such as cost-effectiveness, antibacterial mechanisms, metabolic effects, toxicity, and the unwanted environmental impacts of nanomaterials, have hindered their applications as antibacterial agents. Effective antibacterial agents have been developed using $\mathrm{Cu}, \mathrm{Te}, \mathrm{Ag}, \mathrm{Au}, \mathrm{Ti}, \mathrm{MgO}$, and $\mathrm{Zn}$-based nanocomposites, which have strong and broadspectrum antibacterial activity (Vimbela et al. 2017). Due to their unique physical and chemical properties, these inorganic nanoparticles are considered as an alternative to several antibiotics. The effectiveness of these materials depends 
on the surface/volume ratio, as well as their dimensions and compositional variations. Studies regarding compositional/ crystalline modifications and surface coatings based on complex chemistry may lead to the generation of effective and sustainable antibacterial agents (Wang et al. 2017).

The exact antimicrobial mechanisms of nanoparticles remain unclear. However, thus far, three different possible mechanisms have been investigated. The first involves free metal ion toxicity, which occurs during the production of free metal ions from the surface of inorganic nanoparticles. The second involves the direct physical interaction between a metal surface and the bacterial cell wall, which can damage the outer membrane. Finally, the thrid involves oxidative stress, which is induced via ROS production. Other mechanisms which may be involved in the antibacterial activity of nanoparticles are shown in Fig. 7. Notably, aerosol-based nanoparticles have been synthesized in response to the issue of antimicrobial resistance and they have attracted great interest for their antibacterial applications. Ag nanoparticles were synthesized using a green aerosol technique, which involves an electrical discharge between two electrodes under a continuous supply of inert gas under ambient conditions (Hontanon et al. 2014). The antibacterial activity of Ag nanoparticles was then tested against both gram-positive (Staphylococcus aureus) and gram-negative (Klebsiella pneumoniae) bacteria and were shown to be significantly effective as bactericidal agents. Ag nanoparticles release toxic $\mathrm{Ag}^{+}$ions, which can cause the inactivation of bacterial proteins and enzymes by interacting with their thiol groups, thereby leading to metabolic disturbances which result in the production of ROS. In addition, after penetrating the cell surface, $\mathrm{Ag}^{+}$ions interact with DNA and induce DNA damage by preventing its replication process (Le Ouay and Stellacci 2015).

$\mathrm{Cu}$ and $\mathrm{Cu}$-based alloys are widely used to control the growth and spread of harmful bacteria. $\mathrm{Cu}$ is a crucial micronutrient for humans but it is very toxic to bacterial cells due to $\mathrm{Cu}^{2+}$ ion-induced ROS production and DNA damage (Graves et al. 2020a, b). Thermal-sprayed $\mathrm{Cu}$ coatings on hospital equipment with different composites have been shown to significantly inhibit the growth of pathogenic microorganisms. Moreover, the antibacterial efficacy of $\mathrm{Cu}$ has been reported to increase when the $\mathrm{Cu}$ content in the nanoparticles is increased (Michels et al. 2005). To reduce the free metal-associated toxicity and enhance their stability, chitosan-coated $\mathrm{Cu}-\mathrm{Ag}$

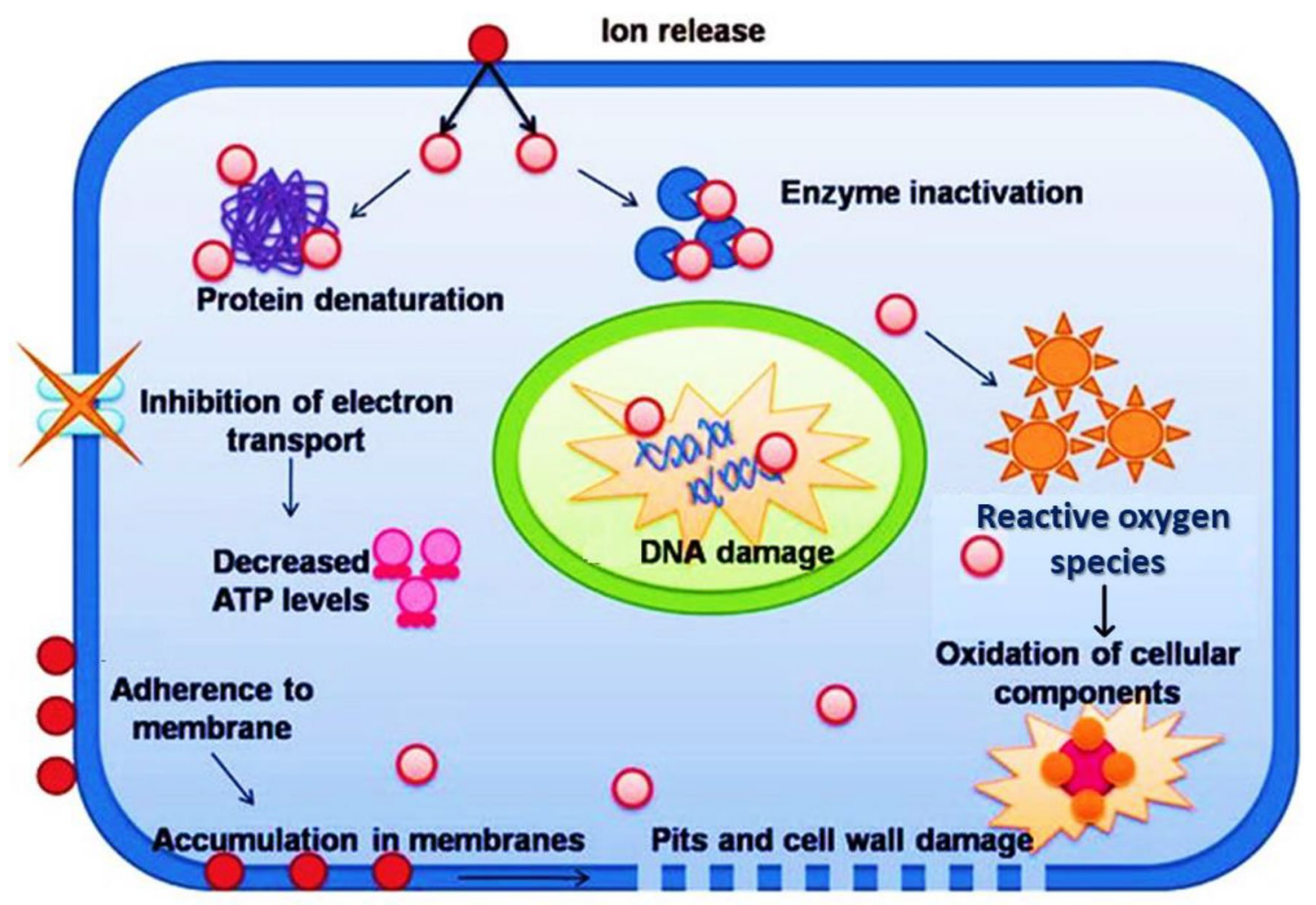

Nanoparticles

Released metal ions

Fig. 7 Different mechanisms of the antimicrobial action of nanoparticles. The given figure was adopted from Jamdagni et al. (2018) 
nanobunches were prepared via a gas-liquid hybrid chemical route under ultrasound irradiation. Chitosan is nonantigenic, biocompatible, nontoxic to human cells, and can easily conjugate with metallic ions. Chitosan-based nanoparticles constructed using various versatile, simple, and green techniques showed the highest antibacterial activity against Escherichia coli and S. aureus, among the different antibacterial nanoparticles. Greater antimicrobial activity was associated with enhanced cellular uptake mediated by the strong electrostatic interaction between chitosan and the bacterial surface (Byeon 2016). Thermoresponsive polymers, such as poly-N-isopropyl acrylamide and poly$\mathrm{N}$-vinyl caprolactam, have been used to develop thermoresponsive antibacterial coatings. Below the transition temperature, these polymers undergo conformational changes to enhance the exposure of bacteria to antibacterial agents. Hence, thermo-responsive antibacterial nanoparticles containing thermo-responsive polymer-incorporated $\mathrm{Ag}$ nano-constructs with silica nanoparticles or carbon nanotubes were fabricated via a single-pass gas-to-liquid process (Poudel et al. 2017). The antibacterial activity of the prepared nanoparticles was evaluated against $E$. coli and Staphylococcus epidermidis and they were shown to be highly effective at higher temperatures. Notably, particle diameter, shape, and surface properties directly influence their effects of the nanoparticles on bacterial cells and surface-modified nanoparticles have been shown to have superior antibacterial activity against resistant strains (Dong et al. 2019). A spark plasma reactor and a flow heater (maintained at room temperature, $400{ }^{\circ} \mathrm{C}$, and 800 ${ }^{\circ} \mathrm{C}$ ) were employed to synthesize $\mathrm{Cu}$-doped $\mathrm{Te}$ nanocomposites with different shapes (Gautam et al. 2019a, b). Using temperature modulation, $\mathrm{Cu}-\mathrm{Te}$ nanoparticles with a dendritic, spiky, or cubic shape were obtained and tested against $E$. coli, extended spectrum $\beta$-lactamase (ESBL)producing E. coli, S. epidermidis, and methicillin-resistant $S$. aureus (MRSA). The prepared $\mathrm{Cu}-\mathrm{Te}$ nanoparticles showed synergistic antibacterial activity due to the release of $\mathrm{Cu}^{2+}$ and $\mathrm{TeO}_{3}{ }^{2-}$ or $\mathrm{TeO}_{4}{ }^{2-}$ ions, when compared to individual $\mathrm{Cu}$ and Te nanoparticles (Gautam et al. 2019a, b) (Table 1).

Although a vast number of nanoparticles have been developed and used for antibacterial purposes, it is necessary to understand their toxicity and outcomes. For a long time, pharmaceutical fields have employed different nanoparticles to minimize the toxicity of the metal components. Nevertheless, there are some safety concerns regarding the use of nanocomposites in biomedical or pharmaceutical fields. Frequently reported toxic effects include respiratory and neurological damage, as well as hematological and nephrological problems, which limit the use of the antibacterial nanocomposites. Indeed, newly developed engineering techniques should be used to prepare antibacterial agents with lower toxicity and better health benefits.

Table 1 List of different formulations used for the treatment of various diseases

\begin{tabular}{|c|c|c|c|}
\hline Preparation/delivery technique & Formulation & Application/treatment & References \\
\hline Collison-type atomizer & BP-H-ILsi-X@EM-YSA & Colon adenocarcinoma (MC-38) & (Ou et al. 2019) \\
\hline $\begin{array}{l}\text { Spark discharge and surface modifica- } \\
\text { tion }\end{array}$ & S-MTN@IG-P & Colon cancer (HT-29 and HCT-116) & (Gautam et al. 2020a, b) \\
\hline $\begin{array}{l}\text { Spark discharge and surface modifica- } \\
\text { tion }\end{array}$ & PB-Dpeg@nGO & Pancreatic cancer (PANC-1) & (Gautam et al. 2020a, b) \\
\hline Single-pass gas-phase self-assembly & nGO@DOX-cPEG & PC3, DU145, and LNCaP tumor cells & (Thapa et al. 2017) \\
\hline Spark ablation & BP@DHCA & Human skin cancers (B-16) & (Nguyen et al. 2019) \\
\hline Green aerosol & Ag-nanoparticles & S. aureus and K. pneumoniae & (Hontanon et al. 2014) \\
\hline Gas-liquid green route & Chitosan-capped $\mathrm{Cu}-\mathrm{Ag}$ nanobunches & E. coli and S. aureus & (Byeon 2016) \\
\hline Spark plasma reactor and flow heater & $\mathrm{Cu}-\mathrm{Te}\left(\mathrm{RT}, 400^{\circ} \mathrm{C}\right.$, or $\left.800^{\circ} \mathrm{C}\right) \mathrm{NPs}$ & $\begin{array}{l}\text { E. coli, ESBL-producing E. coli, } S \text {. } \\
\text { epidermidis, and MRSA }\end{array}$ & (Gautam et al. 2019a, b) \\
\hline Single-pass gas-to-liquid process & Ag-SNP@TRP and Ag-CNT@TRP & E. coli and S. epidermidis & (Poudel et al. 2017) \\
\hline $\begin{array}{l}\text { Spray-congealing with wide pneu- } \\
\text { matic nozzle }\end{array}$ & $\begin{array}{l}\text { Polymer-lipid mucoadhesive micro- } \\
\text { spheres }\end{array}$ & Candida albicans & (Albertini et al. 2009) \\
\hline Aerosol & Aerosolized amphotericin B & $\begin{array}{l}\text { Antifungal prophylaxis in the early } \\
\text { post lung transplantation }\end{array}$ & (Drew et al. 2004) \\
\hline Aerosol & Amphotericin B liposome & $\begin{array}{l}\text { Prevention of invasive pulmonary } \\
\text { aspergillosis in neutropenia }\end{array}$ & (Rijnders et al. 2008) \\
\hline Transdermal spray & Voriconazole transdermal spray & Candida albicans & (Mori et al. 2017) \\
\hline Inhalable dry powder & $\begin{array}{l}\text { Controlled Release Voriconazole Dry } \\
\text { Powder }\end{array}$ & Invasive pulmonary aspergillosis & (Arora et al. 2015) \\
\hline $\begin{array}{l}\text { Ionic gelation using spray drying } \\
\text { technique }\end{array}$ & $\begin{array}{l}\text { Itraconazole encapsulated chitosan- } \\
\text { based dry powder }\end{array}$ & $\begin{array}{l}\text { Pulmonary drug delivery for fungal } \\
\text { infection }\end{array}$ & (Jafarinejad et al. 2012) \\
\hline
\end{tabular}




\section{Antifungal applications}

Nanotechnology has led to the development of several antifungal agents which have been used to treat different fungal infections caused by Candida, dermatophytes, Pityrosporum, and other strains. For decades, numerous antifungal agents, such as griseofulvin, which acts by disturbing spindle and cytoplasmic microtubule function, amphotericin $\mathrm{B}$ and ketoconazole, which act by binding or depleting ergosterol, and terbinafine, which induces squalene accumulation, were continuously used to treat fungal infections (Ali Malayeri et al. 2018). The main concern regarding the use of conventional antifungal agents in a clinical setting is the development of antifungal multidrug resistance. The molecular mechanism of multidrug resistance is associated with alterations in drug target abundance, drug affinity, decreased intracellular drug levels caused by efflux pumps, and biofilm formation (Cowen et al. 2014). To counter this problem, aerosol-based methods have been employed to modify the nature of conventional antifungal agents. These techniques are gaining popularity due to the unique physical and chemical properties of these novel nanoparticles. As the particle size of the nanoparticles decreases, their surface-to-volume ratio increases, which leads to improved antifungal activity (Suresh et al. 2016). Polymer lipid-based microspheres were prepared via a spray-congealing process using a pneumatic nozzle (Albertini et al. 2009). Different mucoadhesive polymers, such as sodium carboxymethylcellulose, chitosan, and poloxamers, were added to a lipid-hydrophilic matrix to enhance the antifungal activity of econazole nitrate for vaginal drug delivery. The prepared microspheres were shown to effectively inhibit Candida albicans with improved solubility and bioavailability. Adverse effects remain a major problem when delivering a drug via different administration routes. This problem was mitigated by delivering amphotericin B in aerosol form in the early stages after lung transplantation, as an antifungal prophylaxis agent (Drew et al. 2004). In addition, a liposomal form of amphotericin $B$ was delivered in an aerosolized form to prevent invasive pulmonary aspergillosis associated with prolonged neutropenia during chemotherapy (Rijnders et al. 2008). Moreover, chitosan, a biocompatible polymer, was utilized to enhance the inhalable dose of itraconazole. Different chitosan and tripolyphosphate ratios were used to prepare the dry powder via spray drying and the prepared formulation was shown to exhibit enhanced pulmonary deposition after inhalation (Jafarinejad et al. 2012). Dermatological fungal infections (e.g., dermatophytoses and candidiasis) are most common in Asian and African countries, affecting approximately $15 \%$ of the total population. The major obstacles to treating these infections include the low efficacy of antifungal agents, poor minimum inhibitory concentrations (MIC), and drug resistance to topical antifungal agents. Therefore, a transdermal spray of voriconazole was prepared using Eudragit RLPO and ethyl cellulose (film-forming polymers) to treat fungal infections (Mori et al. 2017). Due to the wide spectrum of voriconazole, an inhalable, sustained-release dry powder was also formulated and delivered to combat invasive pulmonary aspergillosis (Arora et al. 2015).

Recently, metal-based nanoparticles, such as $\mathrm{Cu}$ (MuñozEscobar and Reyes-López 2020), Pd (Osonga et al. 2020), and $\mathrm{Ag}$ (Suresh et al. 2016) nanoparticles, have been used to treat fungal infections because they can be easily modified and have high stability, low toxicity, low price, and durability. To enhance antifungal activity, an Ag-based ketoconazole gel had been prepared and tested against Malassezia furfur, which is responsible for dermal infections (Mussin et al. 2019). The prepared gel was shown to exhibit synergistic fungicidal action with low MIC values than conventional dosage forms. Recently, chitosan-coupled $\mathrm{Cu}$ nanoparticles were fabricated via an ion gelation technique using sodium tripolyphosphate (Vanti et al. 2020). The toxicity of individual $\mathrm{Cu}$ nanoparticles was found to be significantly decreased after chitosan coating, while their activity against the damping off disease was highly enhanced. Although several types of nanoparticles have been developed to treat fungal infections, the safety of metal-based nanoparticles remains a challenging issue. The development of surface-modified noble metal nanoparticles via aerosol techniques could represent a milestone in the treatment of multidrug-resistant fungal infections.

\section{Antiviral applications}

The recurrence of pathogenic resistance, including that of viruses, is a major cause of death and a serious challenge to medical science. Many efforts have been made to develop stable drugs and vaccines against re-emerging viruses but the development of cheap, novel, and broad-spectrum antiviral agents remains difficult. Current developments in nanomedicine offer a novel platform for the synthesis of potentially effective antiviral metal nanoparticles via appropriate surface modifications. Metal nanoparticles act as antiviral agents by inhibiting viral replication. The antiviral properties of metal nanoparticles are ascribed to the release of free metal ions, which leads to the production of ROS, resulting in the oxidation of capsid proteins (Rai et al. 2016).

$\mathrm{Ag}$ nanoparticles are one of the best candidates for antiviral agents due to their broad range of action. They have been shown to have effective inhibitory activity against severe acute respiratory syndrome-coronavirus (SARS-CoV), influenza $\mathrm{A} / \mathrm{H} 1 \mathrm{~N} 1$, influenza $\mathrm{A} / \mathrm{H} 5 \mathrm{~N} 1$, hepatitis B virus, and human immunodeficiency virus (Haider and Kang 2015; Verma and Maheshwari 2019). The interaction between the Ag nanoparticle and the virus particle also plays a vital role and it has been shown that the smaller nanoparticles 
have more effective antiviral activity. Moreover, it has been reported that conjugation of Ag nanoparticles with different polymers has a beneficial role in antiviral treatment (Salleh et al. 2020). Polyvinylpyrrolidone (PVP)-coated Ag nanoparticles have been shown to effectively inhibit the respiratory syncytial virus. The proposed underlying mechanism of action involves the interaction between PVP-coated Ag nanoparticles and $G$ proteins on the viral surface, which suppresses the attachment of the virus to the host cells (Haider and Kang 2015). Chitin/chitosan-based Ag nanoparticles have also been shown to exert enhanced antiviral activity (Nakamura et al. 2019). Furthermore, Ag-coated nanoparticles have been widely used in industrial applications. The spark discharge technique was used to produce Ag nanoparticles for air-filter coatings. The antiviral activity of the Ag-coated filter was tested against aerosolized bacteriophage MS2 virus particles and it was shown to significantly reduce viral loads (Joe et al. 2016). The same strain of virus was also killed using a carbon nanotube-coated glass fiber prepared via an electro-aerodynamic deposition technique under ambient conditions (Park and Hwang 2014). Recently, specific viral antigens immobilized on reduced GO biosensors via the aerosol jet nano-printing technique were used to detect COVID-19 antibodies within seconds (Ali et al. 2020). It was also shown that $\mathrm{Cu}$ can inhibit the replication of SARS-CoV-2, MERS, or influenza and $\mathrm{Cu}$ oxide can be used in face masks, protective clothing, and filters to prevent bacterial and viral transmission (Cortes and Zuñiga 2020). $\mathrm{Cu}$-coating (approximately $0.05 \mathrm{~mm}$ thick) of aluminum substrates via the cold-spray surface coating method has also been used to inactivate the influenza A virus through a contact-killing mechanism (Sundberg et al. 2015). In addition, $\mathrm{Au}$ and other metal particles are extensively used as antiviral agents, which suggests that this field has great potential for the development of novel antiviral treatments.

\section{Clinical diagnostics}

Several metal nanoparticles are readily implemented in a clinical setting as theragnostic agents due to their small size and unique physicochemical properties. The combination of diagnosis and therapy has a crucial role in cancer diagnosis and treatment. Several nanoparticles ( $\mathrm{Au}$, iron, quantum dots, inorganic phosphor, copper, and other metals) have been used to detect cancer markers, such as circulating tumor cells, vesicles, nucleic acids, and proteins (Huang et al. 2017). Recently, different features have been added to single particles to improve their diagnostic and imaging capabilities. Thus, the multiple properties of plasmonic magnetic nanoparticles are attracting considerable attention in bioimaging, diagnosis, and targeted drug delivery. Previously, silica-coated dumbbell-like $\mathrm{Ag}-\mathrm{Fe}_{2} \mathrm{O}_{3}$ bio-probes were synthesized using the flame aerosol technique for bioimaging and drug delivery (Sotiriou et al. 2011). The purpose of the silica coating was to reduce the release of toxic $\mathrm{Ag}^{+}$from the surface of the nanocomposite. Here, the thin nano-silica coating did not hamper the magnetic and plasmonic properties of the nanoparticles. Size-controlled plasmonic Ag nanoparticles were prepared using the aerosol method. By using the evaporation-condensation system, monodispersed and spherical Ag nanoparticles were prepared and their sizes were measured using a differential mobility analyzer. The dipole peak of the plasmon resonance changed between the wavelengths of 398 and $448 \mathrm{~nm}$ (Harra et al. 2012). Among the various metal nanoparticles, Au nanoparticles possess unique optical and surface plasmon resonance properties. Consequently, they have been considered for applications in the biomedical and diagnostic fields. Moreover, due to their optical properties, Au nanoparticles are utilized in imagingbased diagnostic methods and for ultrasensitive detection in the treatment of cancer and other lethal diseases. Studies have been conducted to prepare ultrapure Au nanoparticles via a pulsed spark-discharge (PSD) technique in the absence of stabilizers and chemical surfactants. Au electrodes were used to generate and condense the vapor within the spark chamber in the presence of a dielectric ethanol medium (Tseng and Huang 2011). Thus, it was shown that PSD can be an alternative green technique for the synthesis of highly stable Au nanoparticles.

Theragnostic approaches have a significant role in personalized therapy due to controlled drug delivery and imaging techniques. MRI is used to detect the presence or progression of various diseases and to maximize therapeutic outcomes, enabling personalized treatment (Ho et al. 2020; Avugadda et al. 2021). Inhalable metal-organic framework nanoparticles were synthesized by spray drying to enhance the localized delivery of antibiotics for tuberculosis treatment. Moreover, the local delivery of a drug into the lungs can be greatly enhanced through MRI contrast agent-guided pulmonary drug delivery systems (Wyszogrodzka-Gaweł et al. 2019). Superparamagnetic reduced $\mathrm{Fe}_{3} \mathrm{O}_{4}$ nanoparticles were synthesized using a gas-phase flame method. Interestingly, this technique produced size-controlled magnetic iron nanoparticles under reduced conditions, which have been widely tested in clinical diagnostics (Kumfer et al. 2010). In another study, iron oxide nanoparticles were obtained via flame pyrolysis of a $\mathrm{Fe}\left(\mathrm{NO}_{3}\right)_{3} \cdot 9 \mathrm{H}_{2} \mathrm{O}$ and $\mathrm{FeC}_{6} \mathrm{H}_{5} \mathrm{O}_{7} \cdot 4 \mathrm{H}_{2} \mathrm{O}$ solution. The synthetic reaction conditions, such as the key precursor solution, solution amount, and reaction environment, were maintained to obtain nanoparticles with a precise particle size, structural phase, and texture (Shen et al. 2020). Recently, the flame spray pyrolysis technique was modified using the SpraySyn nozzle. Iron oxide nanoparticles were prepared using a phase-selective laser-induced breakdown spectroscopy method by varying the composition of spray solution (Stodt et al. 2020). Different types of 
iron oxide nanoparticles, such as ferumoxide, ferucarbotran, and ferumoxytol, have been approved for clinical diagnostic applications (Liu et al. 2020). Hopefully, the continuous development of aerosol-based technologies can pave the way for the production of useful diagnostic agents for clinical application.

\section{Biological assays}

Bioassays determine the relative strength of a substance, either qualitatively or quantitatively, in the test organisms, by comparing with a standard. Biological assays are used to determine the concentration, biological activity, or purity of different compounds in cells, tissues, organisms, or receptors (Dafale 2016; Serrano et al. 2020). Organic and inorganic nanoparticles have been used for analytical detection assays and bioassays. The unique optoelectronic (metal nanoparticles), catalytic (metal, quantum dots, and oxide nanoparticles), magnetic (cobalt and iron oxide nanoparticles), and other physicochemical properties make metal nanoparticles particularly useful for chemical and biological detection when combined with other specific probes (Castro et al. 2014). Due to the surface plasmon resonance properties of $\mathrm{Au}$ and $\mathrm{Ag}$ nanoparticles, they have high extinction coefficients and exhibit different colors in the visible light region of the spectrum. A well-designed aptamer-conjugated $\mathrm{Au}$ nanoparticle was prepared for the direct detection of cancer cells using a colorimetric assay. The assay showed excellent sensitivity and selectivity and was able to distinguish between cancerous and non-cancerous samples. Similarly, dopamine-stabilized Ag nanoparticles have also been proposed to detect melamine in milk samples (Gasparyan 2009; Vilela et al. 2012). Ag-nanoparticle-based nanosensors have also been developed to detect serum p53 levels, which are associated with head and neck squamous cell carcinoma (Zhou et al. 2011). Moreover, photoluminescent Ag nanoparticles were synthesized to detect hydrogen peroxide via fluorescence. Then, the method was coupled with glucose oxidase to determine serum glucose levels (Zhou et al. 2021). The levels of organophosphate pesticides have also been detected using $\mathrm{Au}$ and $\mathrm{Ag}$ nanoparticles via colorimetric analysis (Che Sulaiman et al. 2020). Core-shell structured luminescent and magnetic nanoparticles were also synthesized using the flame spray pyrolysis technique for immunological assays. The prepared nanoparticles have magnetic cores of iron oxide doped with cobalt and neodymium and luminescent shells of europium-doped gadolinium oxide (Eu: $\mathrm{Gd}_{2} \mathrm{O}_{3}$ ). Interestingly, magnetic/luminescent core/ shell particles have several potential biological applications, including the easy detection of bacteria, viruses, and cells (Dosev et al. 2007). Finally, detection assays are directly dependent on the properties of the nanoparticles and for correct interpretation of the results, both quantitative and qualitative changes should be thoroughly monitored.

\section{Conclusion}

This review encompasses various synthesis approaches and biomedical applications of aerosol-based nanoparticles in different fields. Various organic and inorganic nanoparticles can be synthesized using different methods, among which the aerosol-based technique is one of the most promising approaches for large-scale manufacturing of highly pure nanoparticles. The ability of the aerosol-based technique to operate in continuous rather than batch-to-batch manufacturing makes it favorable for industrial and technological applications. In this regard, the utilization of aerosol-based nanoparticles can be highly beneficial to the biomedical field. Aerosol technology presents an innovative and modern approach to develop and test different nanoparticle formulations with anticancer, antibacterial, antiviral, and antifungal properties. The prepared nanoparticles have also been shown to have significant potential as diagnostic agents and in biological assays. Moreover, the theragnostic properties of nanoparticles have facilitated the timely detection of lethal diseases and have proven to be helpful for the early treatment of these diseases.

Acknowledgements This work was supported by the National Research Foundation (NRF) of South Korea Grant funded by the Korean Government (NRF-2018R1A2A2A05021143). This research was also supported by the Medical Research Center Program (2015R1A5A2009124) through the NRF, funded by the Ministry of Science, ICT and Future Planning, South Korea.

\section{Declarations}

Conflict of interest The authors (M. Gautam, J.O. Kim, and C.S. Yong) declare that they have no conflict of interest.

Research involving human and/or animal participants This article does not contain any studies with human participants or animals performed by any of the authors.

\section{References}

Albertini B, Passerini N, Di Sabatino M, Vitali B, Brigidi P, Rodriguez L (2009) Polymer-lipid based mucoadhesive microspheres prepared by spray-congealing for the vaginal delivery of econazole nitrate. Eur J Pharm Sci 36:591-601

Ali Malayeri F, Rezaei A, Raiesi O (2018) Antifungal agents: polyene, azole, antimetabolite, other and future agents. J Bas Res Med Sci 5(2):48-55

Ali MA, Hu C, Jahan S, Yuan B, Saleh MS, Ju E, Gao S-J, Panat R (2020) Sensing of COVID-19 Antibodies in seconds via aerosol jet nanoprinted reduced-graphene-oxide-coated 3D electrodes. Adv Mater. https://doi.org/10.1002/adma.202006647 
An W-J, Thimsen E, Biswas P (2010) Aerosol-chemical vapor deposition method for synthesis of nanostructured metal oxide thin films with controlled morphology. J Phys Chem Lett 1:249-253

Arora S, Haghi M, Loo C-Y, Traini D, Young PM, Jain S (2015) Development of an inhaled controlled release voriconazole dry powder formulation for the treatment of respiratory fungal infection. Mol Pharmaceut 12:2001-2009

Athanassiou EK, Grass RN, Stark WJ (2010) Chemical aerosol engineering as a novel tool for material science: from oxides to salt and metal nanoparticles. Aerosol Sci Technol 44:161-172

Avugadda SK, Wickramasinghe S, Niculaes D, Ju M, Lak A, Silvestri N, Nitti S, Roy I, Samia ACS, Pellegrino T (2021) Uncovering the magnetic particle imaging and magnetic resonance imaging features of iron oxide nanocube clusters. Nanomaterials 11:62

Banerjee S, Adhikari E, Sapkota P, Sebastian A, Ptasinska S (2020) Atmospheric pressure plasma deposition of TiO2: a review. Materials 13:2931

Bettini LG, Dozzi MV, Foglia FD, Chiarello GL, Selli E, Lenardi C, Piseri P, Milani P (2015) Mixed-phase nanocrystalline TiO2 photocatalysts produced by flame spray pyrolysis. Appl Catal B Environ 178:226-232

Blanquart T, de Roest D (Google Patents, 2019)

Byeon JH (2016) Rapid green assembly of antimicrobial nanobunches. Sci Rep 6:1-7

Byeon JH, Kim Y-W (2012) Aerosol copper initiated core-shell nanoparticle synthesis and micropatterning. New J Chem 36:2184-2187

Byeon JH, Kim Y-W (2014) Au-TiO2 nanoscale heterodimers synthesis from an ambient spark discharge for efficient photocatalytic and photothermal activity. ACS Appl Mater Interfaces 6:763-767

Bystrzejewski M, Cudziło S, Huczko A, Lange H, Soucy G, CotaSanchez G, Kaszuwara W (2007) Carbon encapsulated magnetic nanoparticles for biomedical applications: Thermal stability studies. Biomol Eng 24:555-558

Castro L, Blázquez ML, González FG, Ballester A (2014) Mechanism and applications of metal nanoparticles prepared by bio-mediated process. Rev Adv Sci 3:199-216

Chang H, Park J-H, Jang HD (2008) Flame synthesis of silica nanoparticles by adopting two-fluid nozzle spray. Colloids Surf A Physicochem Eng 313-314:140-144

Chawdhury P, Bhargavi K, Subrahmanyam C (2020) Enhanced synergy by plasma reduced Pd nanoparticles on in-plasma catalytic methane conversion to liquid oxygenates. Catal Commun 147:106139

Che Sulaiman IS, Chieng BW, Osman MJ, Ong KK, Rashid JIA, Wan Yunus WMZ, SaM N, NaM K, Halim NA, Mohamad A (2020) A review on colorimetric methods for determination of organophosphate pesticides using gold and silver nanoparticles. Microchim Acta 187:131

Cheng Y, Shigeta M, Choi S, Watanabe T (2012) Formation mechanism of titanium boride nanoparticles by RF induction thermal plasma. Chem Eng J 183:483-491

Cortes AA, Zuñiga JM (2020) The use of copper to help prevent transmission of SARS-coronavirus and influenza viruses. A general review. Diagn Microbiol Infect Dis 98:115176

Cowen LE, Sanglard D, Howard SJ, Rogers PD, Perlin DS (2014) Mechanisms of antifungal drug resistance. Cold Spring Harb Perspect Med 5:a019752-a019752

Darwish AM, Sagapolutele MT, Sarkisov S, Patel D, Hui D, Koplitz B (2013) Double beam pulsed laser deposition of composite films of poly(methyl methacrylate) and rare earth fluoride upconversion phosphors. Compos Part B Eng 55:139-146

Dong Y, Zhu H, Shen Y, Zhang W, Zhang L (2019) Antibacterial activity of silver nanoparticles of different particle size against Vibrio Natriegens. PLoS ONE 14(9):e0222322

Dosev D, Nichkova M, Dumas RK, Gee SJ, Hammock BD, Liu K, Kennedy IM (2007) Magnetic/luminescent core/shell particles synthesized by spray pyrolysis and their application in immunoassays with internal standard. Nanotechnology 18:055102

Drew RH, Dodds Ashley E, Benjamin DK Jr, Davis RD, Palmer SM, Perfect JR (2004) Comparative safety of amphotericin B lipid complex and amphotericin B deoxycholate as aerosolized antifungal prophylaxis in lung-transplant recipients. Transplantation 77:232-237

Dzimitrowicz A, Bielawska-Pohl A, Pohl P, Jermakowicz-Bartkowiak D, Jamroz P, Malik-Gajewska M, Klimczak A, Cyganowski PJPC, Processing P (2020) Application of oil-in-water nanoemulsion carrying size-defined gold nanoparticles synthesized by non-thermal plasma for the human breast cancer cell lines migration and apoptosis. Plasma Chem Plasma P 40:1037-1062

Fazio E, Gökce B, De Giacomo A, Meneghetti M, Compagnini G, Tommasini M, Waag F, Lucotti A, Zanchi CG, Ossi PMJN (2020) Nanoparticles engineering by pulsed laser ablation in liquids: concepts and applications. Nanomaterials 10:2317

Filho PIO, Carmalt CJ, Angeli P, Fraga ES (2020) Mathematical modeling for the design and scale-up of a large industrial aerosolassisted chemical vapor deposition process under uncertainty. Ind Eng Chem Res 59:1249-1260

Gasparyan VK (2009) Gold and silver nanoparticles in bioassay, cell visualization and therapy. Curr Clin Pharmacol 4:159-163

Gautam M, Ku SK, Kim JO, Byeon JH (2018) A scalable on-demand platform to assemble base nanocarriers for combination cancer therapy. Nanoscale 10:11737-11744

Gautam M, Park DH, Park SJ, Nam KS, Park GY, Hwang J, Yong CS, Kim JO, Byeon JH (2019a) Plug-in safe-by-design nanoinorganic antibacterials. ACS Nano 13:12798-12809

Gautam M, Thapa RK, Poudel BK, Gupta B, Ruttala HB, Nguyen HT, Soe ZC, Ou W, Poudel K, Choi H-G, Ku SK, Yong CS, Kim JO (2019b) Aerosol technique-based carbon-encapsulated hollow mesoporous silica nanoparticles for synergistic chemophotothermal therapy. Acta Biomater 88:448-461

Gautam M, Gupta B, Soe ZC, Poudel K, Maharjan S, Jeong J-H, Choi H-G, Ku SK, Yong CS, Kim JO (2020a) Stealth polymer-coated graphene oxide decorated mesoporous titania nanoplatforms for in vivo chemo-photodynamic cancer therapy. Pharm Res 37:162

Gautam M, Poudel BK, Soe ZC, Poudel K, Maharjan S, Ku SK, Yong CS, Joo SW, Kim JO, Byeon JH (2020b) Facile processing for instant production of clinically-approvable nanoagents for combination cancer therapy. Chem Eng J 383:123177

Graves B, Engelke S, Jo C, Baldovi HG, De La Verpilliere J, De Volder M, Boies A (2020a) Plasma production of nanomaterials for energy storage: continuous gas-phase synthesis of metal oxide CNT materials via a microwave plasma. Nanoscale 12:5196-5208

Graves JL Jr, Ewunkem AJ, Thomas MD, Han J, Rhinehardt KL, Boyd S, Edmundson R, Jeffers-Franci L, Harrison SH (2020b) Evolution in action: past, present and future. Springer, Cham, pp 91-106

Haider A, Kang I-K (2015) Preparation of silver nanoparticles and their industrial and biomedical applications: a comprehensive review. Adv Mater Sci 2015:165257

Harra J, Mäkitalo J, Siikanen R, Virkki M, Genty G, Kobayashi T, Kauranen M, Mäkelä JM (2012) Size-controlled aerosol synthesis of silver nanoparticles for plasmonic materials. J Nanopart Res 14:870

Ho D, Quake SR, Mccabe ERB, Chng WJ, Chow EK, Ding X, Gelb BD, Ginsburg GS, Hassenstab J, Ho C-M, Mobley WC, Nolan GP, Rosen ST, Tan P, Yen Y, Zarrinpar A (2020) Enabling technologies for personalized and precision medicine. Trends Biotechnol 38:497-518

Hontanon E, Feng J, Blanes M, Guo X, Santos L, Schmidt-Ott A, Nirschl H, Kruis F (2014) Aerosol route to antibacterial nanosilver coating of cotton fabrics. Sumy State University, Sumy 
Huang X, Liu Y, Yung B, Xiong Y, Chen X (2017) Nanotechnologyenhanced no-wash biosensors for in vitro diagnostics of cancer. ACS Nano 11:5238-5292

Jafarinejad S, Gilani K, Moazeni E, Ghazi-Khansari M, Najafabadi AR, Mohajel N (2012) Development of chitosan-based nanoparticles for pulmonary delivery of itraconazole as dry powder formulation. Powder Technol 222:65-70

Jamdagni P, Sidhu PK, Khatri P, Nehra K, Rana JS (2018) Metallic nanoparticles: potential antimicrobial and therapeutic agents. Adv Animal Biotechnol Appl 143-160

Joe YH, Park DH, Hwang J (2016) Evaluation of Ag nanoparticle coated air filter against aerosolized virus: anti-viral efficiency with dust loading. J Hazard Mater 301:547-553

Kakiuchi H, Ohmi H, Yasutake K (2013) Atmospheric-pressure lowtemperature plasma processes for thin film deposition. J Vac Sci Technol A 32:030801

Kemp IC, Wadley R, Hartwig T, Cocchini U, See-Toh Y, Gorringe L, Fordham K, Ricard F (2013) Experimental study of spray drying and atomization with a two-fluid nozzle to produce inhalable particles. Dry Technol 31:930-941

Khade BS, Mathe VL, Dongre PM (2017) $\alpha$-amylase binding to thermal plasma synthesized zinc oxide nanosheets: a fluorescence study. J Lumin 187:449-456

Khan I, Saeed K, Khan I (2019) Nanoparticles: properties, applications and toxicities. Arab J Chem 12:908-931

Kim H-U, Kulkarni A, Ha S, Shin D, Kim T (2017) Note: electric field assisted megasonic atomization for size-controlled nanoparticles. Rev Sci Instrum 88:076106

Kim T-H, Oh J-H, Kim M, Hong S-H, Choi S (2020) Thermal plasma synthesis of ceramic nanomaterials. Appl Sci Converg Technol 29:117-123

Kumfer BM, Shinoda K, Jeyadevan B, Kennedy IM (2010) Gas-phase flame synthesis and properties of magnetic iron oxide nanoparticles with reduced oxidation state. Aerosol Sci 41:257-265

Le Ouay B, Stellacci F (2015) Antibacterial activity of silver nanoparticles: a surface science insight. NanoToday 10:339-354

Li D, Wang C, Lu Z, Song M, Xia W, Xia W (2020) Synthesis of graphene flakes using a non-thermal plasma based on magnetically stabilized gliding arc discharge. Fuller Nanotub Carbon Nanostruct 20:846-856

Liu L, Jin R, Duan J, Yang L, Cai Z, Zhu W, Nie Y, He J, Xia C, Gong Q, Song B, Anderson JM, Ai H (2020) Bioactive iron oxide nanoparticles suppress osteoclastogenesis and ovariectomy-induced bone loss through regulating the TRAF6-p62-CYLD signaling complex. Acta Biomater 103:281-292

Maiti D, Tong X, Mou X, Yang K (2019) Carbon-based nanomaterials for biomedical applications: a recent study. Front Pharmacol 9:1401

Meierhofer F, Mädler L, Fritsching U (2020) Nanoparticle evolution in flame spray pyrolysis-process design via experimental and computational analysis. AIChE J 66:e16885

Messing ME (2015) The advantages of spark discharge generation for manufacturing of nanoparticles with tailored properties. J Green Eng 5:83-96

Michels H, Wilks S, Noyce J, Keevil C (2005) Copper alloys for human infectious disease control. Stainless Steel 77000(27):20

Mohammadi M (2020) Flame aerosol synthesis of metal-containing nanomaterials, State University of New York at Buffalo 28089044

Mori NM, Patel P, Sheth NR, Rathod LV, Ashara KC (2017) Fabrication and characterization of film-forming voriconazole transdermal spray for the treatment of fungal infection. Bull Faculty Pharm Cairo Univ 55:41-51

Müller M, Galář P, Stuchlík J, Kočka J, Kupka J, Kůsová K (2020) Synthesis and surface modification of light emitting silicon nanoparticles using non-thermal plasma techniques. Eur Phys J Appl Phys 89:20401

Muñoz-Escobar A, Reyes-López SY (2020) Antifungal susceptibility of Candida species to copper oxide nanoparticles on polycaprolactone fibers (PCL-CuONPs). PLoS ONE 15:e0228864

Mussin JE, Roldán MV, Rojas F, Sosa MDLÁ, Pellegri N, Giusiano G (2019) Antifungal activity of silver nanoparticles in combination with ketoconazole against Malassezia furfur. AMB Express 9:131

Nakamura S, Sato M, Sato Y, Ando N, Takayama T, Fujita M, Ishihara M (2019) Synthesis and application of silver nanoparticles (Ag NPs) for the prevention of infection in healthcare workers. Int J Mol Sci 20:3620

Naz MY, Shukrullah S, Ghaffar A, Ali K, Sharma S (2020) Synthesis and processing of nanomaterials. In: Sharma S, Ali K (eds) Solar cells. Springer, Cham, pp 1-23

Nguyen HT, Byeon JH, Phung CD, Pham LM, Ku SK, Yong CS, Kim JO (2019) Method for the instant in-flight manufacture of black phosphorus to assemble core@ shell nanocomposites for targeted photoimmunotherapy. ACS Appl Mater Interfaces $11: 24959-24970$

Dafale NA, Semwal UP, Rajput RK, Singh GN (2016) Selection of appropriate analytical tools to determine the potency and bioactivity of antibiotics and antibiotic resistance. J Pharm Anal 6:207-213

Ogugua SN, Ntwaeaborwa OM, Swart HC (2020) Latest Development on Pulsed Laser Deposited Thin Films for Advanced Luminescence Applications. Coatings 10:1078

Osonga FJ, Kalra S, Miller RM, Isika D, Sadik OA (2020) Synthesis, characterization and antifungal activities of eco-friendly palladium nanoparticles. RSC Adv 10:5894-5904

Ou W, Byeon JH, Soe ZC, Kim BK, Thapa RK, Gupta B, Poudel BK, Ku SK, Yong CS, Kim JO (2019) Tailored black phosphorus for erythrocyte membrane nanocloaking with interleukin- $1 \alpha$ siRNA and paclitaxel for targeted, durable, and mild combination cancer therapy. Theranostics 9:6780-6796

Palma V, Cortese M, Renda S, Ruocco C, Martino M, Meloni E (2020) A review about the recent advances in selected nonthermal plasma assisted solid-gas phase chemical processes. Nanomaterials 10:1596

Park K-T, Hwang J (2014) Filtration and inactivation of aerosolized bacteriophage MS2 by a CNT air filter fabricated using electroaerodynamic deposition. Carbon 75:401-410

Park DH, Gautam M, Park SJ, Hwang J, Yong CS, Kim JO, Byeon JH (2019) Plug-and-play safe-by-design production of metal-doped tellurium nanoparticles with safer antimicrobial activities. Environ Sci Nano 6:2074-2083

Piras CC, Fernández-Prieto S, De Borggraeve WM (2019) Ball milling: a green technology for the preparation and functionalisation of nanocellulose derivatives. Nanoscale Adv 1:937-947

Poudel BK, Park JH, Byeon JH (2017) On-demand gas-to-liquid process to fabricate thermoresponsive antimicrobial nanocomposites and coatings. ACS Appl Mater Interfaces 9:15342-15349

Poudel K, Banstola A, Tran TH, Thapa RK, Gautam M, Ou W, Pham LM, Maharjan S, Jeong J-H, Ku SK, Choi H-G, Yong CS, Kim JO (2020) Hyaluronic acid wreathed, trio-stimuli receptive and on-demand triggerable nanoconstruct for anchored combinatorial cancer therapy. Carbohydr Polym 249:116815

Rai M, Deshmukh SD, Ingle AP, Gupta IR, Galdiero M, Galdiero S (2016) Metal nanoparticles: the protective nanoshield against virus infection. Crit Rev Microbiol 42:46-56

Rijnders BJ, Cornelissen JJ, Slobbe L, Becker MJ, Doorduijn JK, Hop WCJ, Ruijgrok EJ, Lüwenberg B, Vulto A, Lugtenburg PJ, De Marie S (2008) Aerosolized liposomal amphotericin B for the prevention of invasive pulmonary aspergillosis during prolonged 
neutropenia: a randomized, placebo-controlled trial. Crit Rev Microbiol 46:1401-1408

Salleh A, Naomi R, Utami ND, Mohammad AW, Mahmoudi E, Mustafa N, Fauzi MB (2020) The potential of silver nanoparticles for antiviral and antibacterial applications: a mechanism of action. Nanomaterials 10:1566

Serrano A, Peces M, Astals S, Villa-Gómez DK (2020) Batch assays for biological sulfate-reduction: a review towards a standardized protocol. Crit Rev Environ Sci Technol 50:1195-1223

Shandilya N, Le Bihan O, Morgeneyer M (2014) A Review on the study of the generation of (nano)particles aerosols during the mechanical solicitation of materials. J Nanomater 2014:289108

Shen J, Shafiq M, Ma M, Chen H (2020) Synthesis and surface engineering of inorganic nanomaterials based on microfluidic technology. Nanomaterials 10:1177

Shields SP, Richards VN, Buhro WE (2010) Nucleation control of size and dispersity in aggregative nanoparticle growth. A Study of the coarsening kinetics of thiolate-capped gold nanocrystals. Chem Mater 22:3212-3225

Sotiriou GA, Hirt AM, Lozach P-Y, Teleki A, Krumeich F, Pratsinis SE (2011) Hybrid, silica-coated, janus-like plasmonic-magnetic nanoparticles. Chem Mater 23:1985-1992

Sportelli MC, Izzi M, Volpe A, Clemente M, Picca RA, Ancona A, Lugarà PM, Palazzo G, Cioffi N (2018) The pros and cons of the use of laser ablation synthesis for the production of silver nanoantimicrobials. Antibiotics 7:67

Stodt MFB, Liu C, Li S, Mädler L, Fritsching U, Kiefer J (2020) Phaseselective laser-induced breakdown spectroscopy in flame spray pyrolysis for iron oxide nanoparticle synthesis. Proc Combust Inst. https://doi.org/10.1016/j.proci.2020.06.092

Stryczewska HD (2020) Supply systems of non-thermal plasma reactors. Construction review with examples of applications. Appl Sci 10:3242

Sundberg K, Champagne V, Mcnally B, Helfritch D, Sisson RJ (2015) Effectiveness of nanomaterial copper cold spray surfaces on inactivation of influenza A virus. J Biotechnol Biomater 5:205

Suresh S, Karthikeyan S, Saravanan P, Jayamoorthy K, Dhanalekshmi KI (2016) Comparison of antibacterial and antifungal activity of 5-amino-2-mercapto benzimidazole and functionalized Ag3O4 nanoparticles. Karbala Int J Modern Sci 2:129-137

Teoh WY, Amal R, Mädler L (2010) Flame spray pyrolysis: an enabling technology for nanoparticles design and fabrication. Nanoscale 2:1324-1347

Thapa RK, Byeon JH, Ku SK, Yong CS, Kim JO (2017) Easy ondemand self-assembly of lateral nanodimensional hybrid graphene oxide flakes for near-infrared-induced chemothermal therapy. NPG Asia Mater 9:e416-e416

Tseng K-H, Huang J-C (2011) Pulsed spark-discharge assisted synthesis of colloidal gold nanoparticles in ethanol. J Nanopart Res 13:2963-2972

Ullmann M, Friedlander SK, Schmidt-Ott A (2002) Nanoparticle formation by laser ablation. J Nanopart Res 4:499-509

Vankayala R, Huang YK, Kalluru P, Chiang CS, Hwang KC (2014) First demonstration of gold nanorods-mediated photodynamic therapeutic destruction of tumors via near infra-red light activation. Small 10:1612-1622
Vanti GL, Masaphy S, Kurjogi M, Chakrasali S, Nargund VB (2020) Synthesis and application of chitosan-copper nanoparticles on damping off causing plant pathogenic fungi. Int J Biol Macromol 156:1387-1395

Veintemillas-Verdaguer S, Leconte Y, Costo R, Bomati-Miguel O, Bouchet-Fabre B, Morales MP, Bonville P, Pérez-Rial S, Rodriguez I, Herlin-Boime N (2007) Continuous production of inorganic magnetic nanocomposites for biomedical applications by laser pyrolysis. J Magn Magn 311:120-124

Verma P, Maheshwari SK (2019) Applications of Silver nanoparticles in diverse sectors. Int J Nano Dimens 10:18-36

Vilela D, González MC, Escarpa A (2012) Sensing colorimetric approaches based on gold and silver nanoparticles aggregation: chemical creativity behind the assay. A review. Anal Chim Acta 751:24-43

Vimbela GV, Ngo SM, Fraze C, Yang L, Stout DA (2017) Antibacterial properties and toxicity from metallic nanomaterials. Int $\mathrm{J}$ Nanomed 12:3941-3965

Wang W-N, Purwanto A, Lenggoro IW, Okuyama K, Chang H, Jang HD (2008) Investigation on the correlations between droplet and particle size distribution in ultrasonic spray pyrolysis. Ind Eng Chem Res 47:1650-1659

Wang L, Hu C, Shao L (2017) The antimicrobial activity of nanoparticles: present situation and prospects for the future. Int J Nanomed 12:1227-1249

Wang H-L, Hsu C-Y, Wu KC, Lin Y-F, Tsai D-H (2020) Functional nanostructured materials: aerosol, aerogel, and de novo synthesis to emerging energy and environmental applications. Adv Powder Technol 31:104-120

Wyszogrodzka-Gaweł G, Dorożyński P, Giovagnoli S, Strzempek W, Pesta E, Węglarz WP, Gil B, Menaszek E, Kulinowski P (2019) An Inhalable theranostic system for local tuberculosis treatment containing an isoniazid loaded metal organic framework Fe-MIL-101-NH2_from raw MOF to drug delivery system. Pharmaceutics 11:687

Yu Vasilyev A, Domrina ES, Kaufman SV, Maiorova AI (2019) Classification of atomization devices. J Phys Conf Ser 1359:012131

Zhang Y-R, Lin R, Li H-J, He W-L, Du J-Z, Wang J (2019) Strategies to improve tumor penetration of nanomedicines through nanoparticle design. WIREs Nanomed Nanobiotechnol 11:e1519

Zhou W, Ma Y, Yang H, Ding Y, Luo X (2011) A label-free biosensor based on silver nanoparticles array for clinical detection of serum p53 in head and neck squamous cell carcinoma. Int J Nanomed 6:381-386

Zhou T, Su Z, Wang X, Luo M, Tu Y, Yan J (2021) Fluorescence detections of hydrogen peroxide and glucose with polyethyleneiminecapped silver nanoclusters. Spectrochim Acta A Mol Biomol Spectrosc 244:118881

Publisher's Note Springer Nature remains neutral with regard to jurisdictional claims in published maps and institutional affiliations. 